\title{
Predictive role of multiple gene alterations in response to cetuximab in metastatic colorectal cancer: A single center study
}

\author{
Paola Ulivi ${ }^{1}$, Laura Capelli ${ }^{1}$, Martina Valgiusti ${ }^{2}$, Wainer Zoli ${ }^{1}$, Emanuela Scarpi ${ }^{3}$, Elisa Chiadini ${ }^{1}$, Paola Rosetti ${ }^{2}$, \\ Sara Bravaccini ${ }^{1}$, Daniele Calistri ${ }^{1}$, Luca Saragoni ${ }^{4}$, Andrea Casadei Gardini ${ }^{2}$, Angela Ragazzini ${ }^{1}$, \\ Giovanni Luca Frassineti ${ }^{2}$, Dino Amadori ${ }^{2}$ and Alessandro Passardi ${ }^{2 *}$
}

\begin{abstract}
Background: KRAS mutations negatively affect outcome after treatment with cetuximab in metastatic colorectal cancer (mCRC) patients. As only 20\% of KRAS wild type (WT) patients respond to cetuximab it is possible that other mutations, constitutively activating the EGFR pathway, are present in the non-responding KRAS WT patients. We retrospectively analyzed objective tumor response rate, (ORR) progression-free (PFS) and overall survival (OS) with respect to the mutational status of KRAS, BRAF, PIK3CA and PTEN expression in mCRC patients treated with a cetuximab-based regimen.

Methods: $67 \mathrm{mCRC}$ patients were enrolled onto the study. DNA was extracted from paraffin-embedded sections derived from primary or metastatic lesions. Exon 2 of KRAS and exon 15 of BRAF were analyzed by direct sequencing, PIK3CA was evaluated by pyrosequencing and PTEN expression by immunohistochemistry.

Results: BRAF and PIK3CA mutations were independently associated with worse PFS ( $p=0.006$ and $p=0.028$, respectively) and $O S$ ( $p=0.008$ and $p=0.029$, respectively). No differences in clinical outcome were found between patients who were positive or negative for PTEN expression. Conversely, patients negative for KRAS, BRAF and PIK3CA mutations were characterized by significantly better ORR, PFS and OS than patients with at least one of these mutations.
\end{abstract}

Conclusions: BRAF and PIK3CA mutations would seem to be independent predictors of anti-EGFR therapy effectiveness and could be taken into consideration during treatment decision making.

Keywords: Metastatic colorectal cancer, Cetuximab, KRAS, BRAF, PIK3CA, PTEN

\section{Background}

Colorectal cancer (CRC) is the third most common form of cancer and the second leading cause of cancer-related death. Although early diagnosis may allow radical surgery to be performed and result in a complete cure, about 25\% of patients present with metastatic disease at diagnosis and about $40-50 \%$ of resected patients will develop distant metastases and die [1]. There is evidence that the use of polychemotherapy with fluoropyrimidines, oxaliplatin

\footnotetext{
* Correspondence: a.passardi@irst.emr.it

${ }^{2}$ Department of Medical Oncology, IRCCS Istituto Scientifico Romagnolo per lo Studio e la Cura dei Tumori (I.R.S.T.), Via Maroncelli 40, 47014 Meldola (FC), Italy

Full list of author information is available at the end of the article
}

and irinotecan can significantly improve overall survival (OS) in patients with metastatic CRC (mCRC) with respect to those who do not receive all three drugs. The use of bevacizumab in association with chemotherapy has also been shown to prolong OS [2].

Current treatment options for mCRC include cetuximab (CTX), a chimeric IgG1 monoclonal antibody which binds to the epidermal growth factor receptor (EGFR), leading to inhibition of its downstream signaling. However, objective response rates (ORRs) in unselected mCRC populations are only around $8-12 \%$ for CTX when used in monotherapy [2-5]. As a number of retrospective studies have shown that somatic mutations of KRAS can negatively affect the efficacy of CTX [6-8], the

\section{Biomed Central}


use of the drug has been restricted by health authorities to patients with wild type (WT) KRAS. Despite this, relatively few patients benefit from CTX: ORRs are around 13\% (vs about $1 \%$ in KRAS mutated) for monotherapy [9] and about $60 \%$ (vs $35 \%$ in KRAS mutated) when combined with chemotherapy $[10,11]$. These findings clearly suggest that other resistance mediators exist in non-responding WT patients. The predictive value of additional mutations and deregulations of signaling pathways downstream of EGFR such as $B R A F, P I K 3 C A$, or PTEN is currently under intensive investigation.

BRAF plays a crucial role in the KRAS pathway and a key mutation (V600E) in exon 15 has been described in colon cancer $[12,13]$. A number of retrospective and preclinical studies have recently suggested that $B R A F$ mutations are mutually exclusive with those of $K R A S$ and may indicate resistance to anti-EGFR therapy in $\mathrm{mCRC}$ patients as well as in cellular models of CRC $[14,15]$. The PIK3CA gene is another downstream effector of $K R A S$ and its pathway is normally inhibited by PTEN. The role of the PIK3CA/PTEN pathway in resistance to EGFR inhibitors has been investigated extensively in KRAS WT patients and cellular models of CRC, with conflicting results [16-22].

We retrospectively analyzed the relation between ORR, progression-free survival (PFS) and OS and the mutational status of KRAS, BRAF, PIK3CA and PTEN expression in mCRC patients treated with a CTX-based regimen, with the aim of clarifying the relative contribution of these molecular alterations to clinical outcome.

\section{Methods}

\section{Patient population and treatment regimens}

We retrospectively analyzed 67 evaluable patients with EGFR-positive mCRC, consecutively treated with a CTXbased regimen at Istituto Scientifico Romagnolo per lo Studio e la Cura dei Tumori in Meldola, Italy, from March 2004 to October 2010. Inclusion criteria were pathological diagnosis of stage IV colorectal adenocarcinoma, age $>18$ years, Eastern Cooperative Oncology Group performance status $<3$. Patients treated before June 2009 were selected for CTX on the basis of EGFR expression alone as KRAS mutational status evaluation had still not been made mandatory by the Italian Regulatory Authority. All patients treated after June 2009 had tumors negative for KRAS mutations.

Data on patient characteristics, treatment and outcome were collected. Treatment was continued until disease progression or toxicity occurred, as per standard criteria. Clinical response was assessed every 8 weeks with complete radiological examination (CT or MRI scan) and was evaluated a posteriori according to Response Evaluation Criteria in Solid Tumors (RECIST) guidelines. Objective tumor responses were classified into partial response (PR), stable disease (SD) or progressive disease (PD). Patients with SD or PD were defined as nonresponders. The ORR was defined as the fraction of patients with complete or partial response confirmed at $\geq$ 4 weeks after the initial response. Toxicity was evaluated according to National Cancer Institute Common Terminology Criteria for Adverse Events v 3.0 guidelines for each patient receiving at least one dose of study treatment.

The study was approved by the local Ethical Committee in accordance with the ethical standards laid down in the 1964 Declaration of Helsinki. All patients gave their written informed consent.

\section{Molecular analyses}

Formalin-fixed paraffin-embedded (FFPE) tumor blocks were reviewed for quality and tumor content. DNA was extracted from 5 - $\mu \mathrm{M}$ FFPE sections of primary or metastatic lesions containing at least $50 \%$ of tumor cells. Exon 2 of $K R A S$ and exon 15 of BRAF genes were amplified by PCR using the following primers: forward 5'-GGT GAG TTT GTA TTA AAA GGT ACT GG-3' and reverse 5' GGT CCT GCA CCA GTA ATA TGC-3' for KRAS, and forward 5' TCA TAA TGC TTG CTC TGA TAG GA-3' and reverse 5'- GGC CAA AAA TTT AAT CAG TGG A-3' for $B R A F$. PCR products were purified using MiniElute PCR purification kit (Qiagen, Hilden, Germany) and then submitted to sequencing using BigDye Terminator 3.1 Reaction Cycle Sequencing kit (Applied Biosystems, Foster City, CA). Sequence reactions were purified using DyeEx 2.0 Spin kit (Qiagen) and separated by capillary electrophoresis with laser-induced fluorescence detection (3100 Genetic Analyzer, Applied Biosystems).

PIK3CA status was analyzed by pyrosequencing using anti-EGFR MoAb response (PIK3CA status) (Diatech, Jesi, Ancona, Italy), according to the manufacturer's instructions. Reactions were run on a PyroMark Q96 ID (Qiagen). PTEN protein expression was analyzed by immunohistochemistry using a Dako monoclonal antibody diluted 1:100. Samples with $\geq 5 \%$ immunopositive neoplastic cells of any intensity in cytoplasm and/or nucleus were considered as PTEN-positive.

\section{Statistical analyses}

A two-sided Fisher's exact test was used to evaluate the association between mutations and ORR. PFS was calculated from the first day of treatment to the date of first observation of disease progression or last follow-up or death in the absence of progressive disease. OS was calculated from the first day of treatment to the date of death of any cause, or last follow-up. PFS, OS and their 95\% confidence intervals (95\% CI) were estimated using the Kaplan-Meier life-table method [23] and survival curves were compared by the logrank test [24]. 
Logistic regression was used to estimate the odds ratio of response to therapy and the 95\% CI for mutational status in univariate analysis. Hazard ratios (HR) and their 95\% CI were estimated according to Cox multiple regression model to evaluate the independent predictive role of mutational status of KRAS, BRAF, PIK3CA and PTEN expression in PFS and OS [25]. Statistical significance was assumed for $p<0.05$. Statistical analyses were carried out with SAS Statistical software (version 9.1, SAS Institute, Cary, NC).

\section{Results}

\section{Molecular alterations}

Among the 39 patients treated with CTX-based treatment before June 2009 we detected 14 (36\%) KRAS mutations, whereas all 28 patients treated after June 2009 had WT KRAS. In the overall series, 10 (71\%) KRAS mutations occurred in codon 12 , of which 4 were G12V, 3 G12S, 2 G12D and 1 G12A alterations. In 4 (29\%) cases mutations occurred in codon 13 and were all G13D alterations. BRAF mutations were detected in 12 (17.9\%) patients and all were V600E alterations. Mutations in the PIK3CA gene were detected in 9 (13.4\%) patients involving exon 9 (4 E545K, 2 E542K, 1 E545G) in 7 cases and exon 20 (both H1047R) in 2 cases. Loss of PTEN expression was observed in 40 (59.7\%) cases.

KRAS and BRAF mutations occurred in a mutually exclusive manner in all but one patient, while an overlapping pattern was observed among the other gene alterations. We observed only one mutation in 28 cases, two overlapping mutations in different combinations in 16 cases and three overlapping alterations in 5 cases. The most frequent overlapping alterations were $B R A F /$ PTEN (9 cases), PIK3CA/PTEN (7 cases) and KRAS/ PIK3CA/PTEN (3 cases) (Figure 1).

\section{Clinical variables}

Clinical characteristics of patients are shown in Table 1. Our cohort included heavily pretreated patients, more than $75 \%$ of whom had received at least 2 lines of chemotherapy for metastatic disease, including irinotecan, oxaliplatin and fluoropyrimidines, and in $38.8 \%$ of cases, bevacizumab. The vast majority of patients (89.5\%) were treated with irinotecan-based chemotherapy plus CTX. Overall there were 17 responders (ORR 25.4\%) and 50 non responders (74.6\% of whom $28.3 \% \mathrm{SD}$ and $46.3 \% \mathrm{PD})$. Analysis of clinical variables showed that only cutaneous toxicity (2-3 vs 0$)$ and ECOG PS (1-2 vs 0$)$ were associated with significantly better median PFS $(p=0.014$ and 0.0007 , respectively). Other clinical variables including gender, site of primary tumor (colon, rectum), age and number of previous cancer treatments for advanced disease were not predictors of clinical outcome.

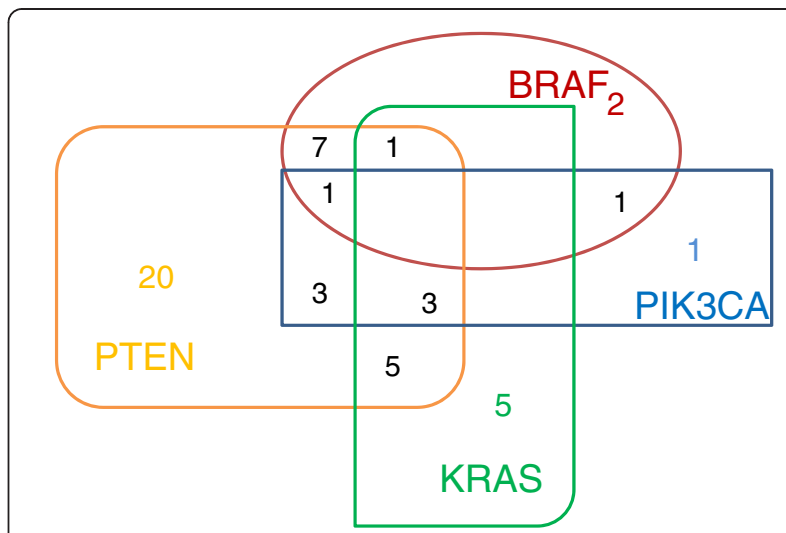

Figure 1 Distribution of different molecular alterations in individual tumors of the 67 patients. KRAS and BRAF mutations occurred in a mutually exclusive manner in all but one patient, while an overlapping pattern was observed among the other gene alterations.

\section{Molecular alterations and clinical outcomes: Univariate analyses}

The role of each molecular alteration is shown in Table 2. We found a better, albeit not statistically significant, ORR in patients with WT tumors with respect to those with $K R A S, B R A F$, or PIK3CA mutations, while no differences were found in PTEN-positive compared to PTEN-negative patients. At a median follow-up of 28 months, 61 cases of progressive disease and 57 deaths had been registered. Median PFS and OS were significantly better in patients with wild type BRAF and PIK3CA. Only a trend towards a better median PFS was observed in patients with wild type KRAS or with high PTEN expression.

\section{Molecular alterations and clinical outcomes: Multivariate analyses}

Multivariate analysis was performed on all 4 molecular alterations and was adjusted for PS, cutaneous toxicity, and number of previous chemotherapy lines. No correlation was found between mutation status and lack of objective response. The analysis did, however, confirm, that wild type BRAF and PIK3CA were significantly and independently associated with better PFS $[\mathrm{HR}=2.65(95 \% \mathrm{CI}$ 1.33-5.29), $p=0.006$ and $\mathrm{HR}=2.46$ (95\% CI 1.10-5.52), $p=0.028$, respectively], with KRAS mutations also exerting a detrimental borderline effect $[\mathrm{HR}=1.86$ (95\% CI 0.99-3.47), $p=0.052]$. Conversely, PTEN expression was not correlated with PFS. With regard to OS, BRAF and PIK3CA mutations were once again associated with decreased survival $[\mathrm{HR}=2.47 \quad(95 \% \quad \mathrm{CI} \quad 1.26-4.85)$, $p=0.008$ and $\mathrm{HR}=2.51$ (95\% CI 1.10-5.72), $p=0.029$, respectively], whereas KRAS and PTEN alterations did not independently affect clinical outcome (Table 3 ).

In accordance with the new patient selection criteria for CTX, we analyzed the effect of BRAF and PIK3CA 
Table 1 Baseline patient characteristics

\begin{tabular}{|c|c|}
\hline & $n(\%)$ \\
\hline No. of patients & 67 \\
\hline Median age, yrs (range) & $61(34-79)$ \\
\hline \multicolumn{2}{|l|}{ Gender (male/female) } \\
\hline Male & $39(58.2 \%)$ \\
\hline Female & $28(41.8 \%)$ \\
\hline \multicolumn{2}{|l|}{ Performance Status } \\
\hline 0 & $37(55.2 \%)$ \\
\hline $1-2$ & $30(44.8 \%)$ \\
\hline \multicolumn{2}{|l|}{ Primary tumor site } \\
\hline Colon & $54(80.6 \%)$ \\
\hline Rectum & $13(19.4 \%)$ \\
\hline \multicolumn{2}{|l|}{ Treatment regimen } \\
\hline$C T X+$ irinotecan/folfiri & $60(89.5 \%)$ \\
\hline CTX + FOLFOX4 & $6(9.0 \%)$ \\
\hline CTX alone & $1(1.5 \%)$ \\
\hline \multicolumn{2}{|l|}{ Previous chemotherapy } \\
\hline Irinotecan-based & $62(92.5 \%)$ \\
\hline Fluoropyrimidine-based & $67(100 \%)$ \\
\hline Oxaliplatin-based & $54(80.6 \%)$ \\
\hline Bevacizumab-based & $26(38.8 \%)$ \\
\hline \multicolumn{2}{|c|}{$\begin{array}{l}\text { No. of previous cancer treatments for } \\
\text { advanced disease }\end{array}$} \\
\hline One & $15(22.4 \%)$ \\
\hline Two & $28(41.8 \%)$ \\
\hline Three & $15(22.4 \%)$ \\
\hline More than three & $9(13.4 \%)$ \\
\hline \multicolumn{2}{|l|}{ Cutaneous toxicity } \\
\hline 0 & $19(32.8 \%)$ \\
\hline 1 & $19(32.8 \%)$ \\
\hline $2-3$ & $20(34.5 \%)$ \\
\hline Unknown & 9 \\
\hline
\end{tabular}

mutations and loss of PTEN on the 53 patients with wildtype KRAS tumors. At multivariate analysis, BRAF mutation was confirmed as a predictor of worse PFS $[\mathrm{HR}=3.15$ (95\% CI 1.51-6.59), $p=0.002]$ and OS [HR $=2.87(95 \% \mathrm{CI}$ 1.37-6.00), $p=0.005$ ] and PIK3CA mutations were correlated with a shorter, albeit not statistically significant, PFS, whereas no correlation was observed with respect to OS. Finally, PTEN expression was not found to affect either PFS or OS.

\section{Number of tumor molecular alterations and clinical outcome}

The contribution of the number of mutations in determining the clinical outcome of patients was examined. In particular, we considered the combination of KRAS,
BRAF and PIK3CA mutations, excluding PTEN expression because of its low impact as an independent predictive marker. Our results showed that 38 (56.7\%) patients did not have any alterations, 23 (34.3\%) had one mutation and $6(9.0 \%)$ had 2 mutations.

Objective response rates were $36.8 \%$ in triple wild type' patients and $13.0 \%$ in those with one mutation, while no responses were observed in patients with 2 mutations. The odds ratio of response was 0.20 (95\% CI $0.05-0.77)(p=0.020)$ in patients with at least one mutation compared to those with no mutations. Similarly, survival analysis showed that patients with at least one mutation had worse PFS and OS with respect to those with none. In particular, median PFS $(95 \% \mathrm{CI})$ was 5.5 (5.1-8.7), 2.9 (2.3-3.6) and 2.2 months (1.1-3.3) for patients harboring no alterations, one or two alterations, respectively, $p<0.001$ (Figure 2). Median OS (95\% CI) was 13.9 (8.3-17.6), 7.3 (5.8-9.5) and 6.4 months (3.7-9.6) for patients harboring no alterations, one or two alterations, respectively, $p=0.001$ (Figure 3 ).

\section{Discussion}

The clinical impact of monoclonal antibodies targeting EGFR in patients with mCRC has been clearly established. In particular CTX, alone or in combination with conventional chemotherapy, has been shown to improve the outcome of patients treated in first-, second- and third-line settings. KRAS mutational status is currently a validated predictive biomarker used to select mCRC patients for EGFR-targeted drugs, such as CTX and panitumumab. However, response rates to either drug are less than $20 \%$ in wild-type $K R A S$ patients. Although recent reports have indicated that BRAF, PIK3CA or

Table 2 Biomolecular alterations and ORR, PFS and OS: univariate analysis

\begin{tabular}{ccccccc}
\hline & $\boldsymbol{n}$ & ORR \% & $\begin{array}{c}\text { Median PFS } \\
\text { (months) } \\
(\mathbf{9 5 \%} \text { Cl) }\end{array}$ & $\boldsymbol{p}$ & $\begin{array}{c}\text { Median OS } \\
\text { (month) } \\
\text { (95\% Cl) }\end{array}$ & $\boldsymbol{p}$ \\
\hline $\begin{array}{c}\text { Overall } \\
\text { KRAS }\end{array}$ & 67 & & $4.3(2.9-5.5)$ & - & $9.2(7.3-12.0)$ & - \\
WT & 53 & 30.2 & $5.2(3.4-6.7)$ & & $8.7(6.9-14.6)$ & \\
Mut & 14 & 7.1 & $2.7(2.2-3.9)$ & 0.070 & $9.4(6.0-12.0)$ & 0.114 \\
BRAF & & & & & & \\
WT & 55 & 29.1 & $5.1(3.2-6.7)$ & & $9.6(8.3-13.9)$ & \\
Mut & 12 & 8.3 & $2.8(1.4-3.9)$ & 0.005 & $5.8(2.1-8.4)$ & 0.008 \\
PIK3CA & & & & & & \\
WT & 58 & 27.6 & $5.1(3.4-6.2)$ & & $9.9(8.3-13.7)$ & \\
Mut & 9 & 11.1 & $2.3(2.1-3.3)$ & 0.031 & $6.6(4.4-7.3)$ & 0.013 \\
PTEN & & & & & & \\
$<5 \%$ & 40 & 22.5 & $3.3(2.3-5.2)$ & & $8.3(6.0-12.4)$ & \\
$\geq 5 \%$ & 27 & 29.6 & $6.2(4.0-8.7)$ & 0.073 & $11.0(8.0-14.6)$ & 0.647 \\
\hline
\end{tabular}


Table 3 Biomolecular alterations and ORR, PFS and OS: multivariate analysis

\begin{tabular}{lcccc}
\hline & $\begin{array}{c}\text { PFS } \\
\text { HR (95\% Cl) }\end{array}$ & $\boldsymbol{p}$ & OS & HR (95\% Cl) \\
\hline KRAS (mutated vs wild type) & $1.86(0.99-3.47)$ & 0.052 & $1.56(0.83-2.96)$ & \\
BRAF (mutated vs wild type) & $2.65(1.33-5.29)$ & 0.006 & $2.47(1.26-4.85)$ & 0.170 \\
PIK3CA (mutated vs wild type) & $2.46(1.10-5.52)$ & 0.028 & $2.51(1.10-5.72)$ & 0.008 \\
PTEN (<5\% vs $\geq 5 \%)$ & $1.47(0.85-2.54)$ & 0.169 & $0.89(0.50-1.57)$ & 0.029 \\
\hline
\end{tabular}

PTEN alterations may constitute additional mechanisms of resistance to these drugs, results are still conflicting [14,15,19-22,26,27]. Our case series included patients with $K R A S$ wt and KRAS mutated tumors treated with CTX before June 2009, and others selected with KRAS wt tumors treated after June 2009. We observed a better, albeit not statistically significant, ORR, OS and PFS in patients with $K R A S$ wt tumors with respect to those with KRAS mutated tumors. This lack of statistical significance may be a result of the limited number of mutated cases due to the selection of wt patients after June 2009. It is also possible that a complex relationship exists between anti-EGFR response and KRAS status due to the synergistic effects of mutant and wild type KRAS proteins [28].

Data were recently published on a subgroup analysis of patients treated with chemotherapy and CTX (trial NCIC CTG CO.17), showing that those with tumors harboring KRAS G13D mutations $(14.5 \%$ of the KRAS mutated group) had better PFS and OS compared to patients with other KRAS mutations. No significant differences in PFS and OS were noted when patients with KRAS G13D mutations were compared with those with wild type $K R A S$ tumors [29]. In our experience 4 patients with $K R A S$ G13D mutation did not respond. No correlations can be made with other types of mutations because of the low number of such mutations found. However, of the four patients with the G12V mutation, which is considered the most aggressive KRAS alteration in colorectal cancer [30,31], only one showed a partial response.

Significantly worse OS and PFS were observed in $B R A F$ or PIK3CA mutated patients, suggesting that these two alterations may play an important role in determining anti-EGFR resistance. In particular, we found a high incidence of $B R A F$ mutations (17.9\%), possibly due to the high prevalence of wild type KRAS tumors which more frequently harbor alterations of the $B R A F$ gene. It

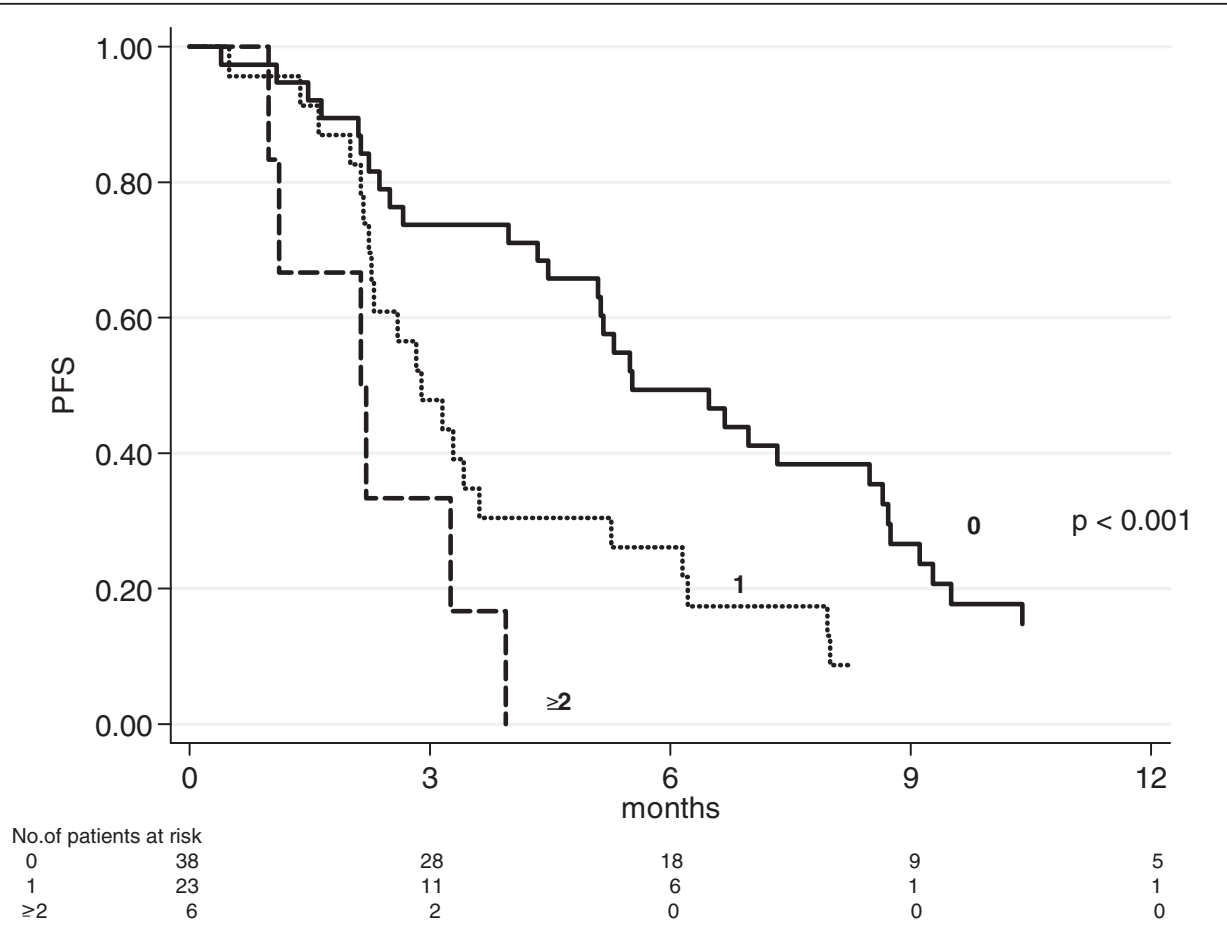

Figure 2 PFS on the basis of the number of tumor molecular alterations. A significant difference $(p<0.001)$ was observed among patients harboring no (5.5 months), one (2.9 months) or two (2.2 months) alterations. 


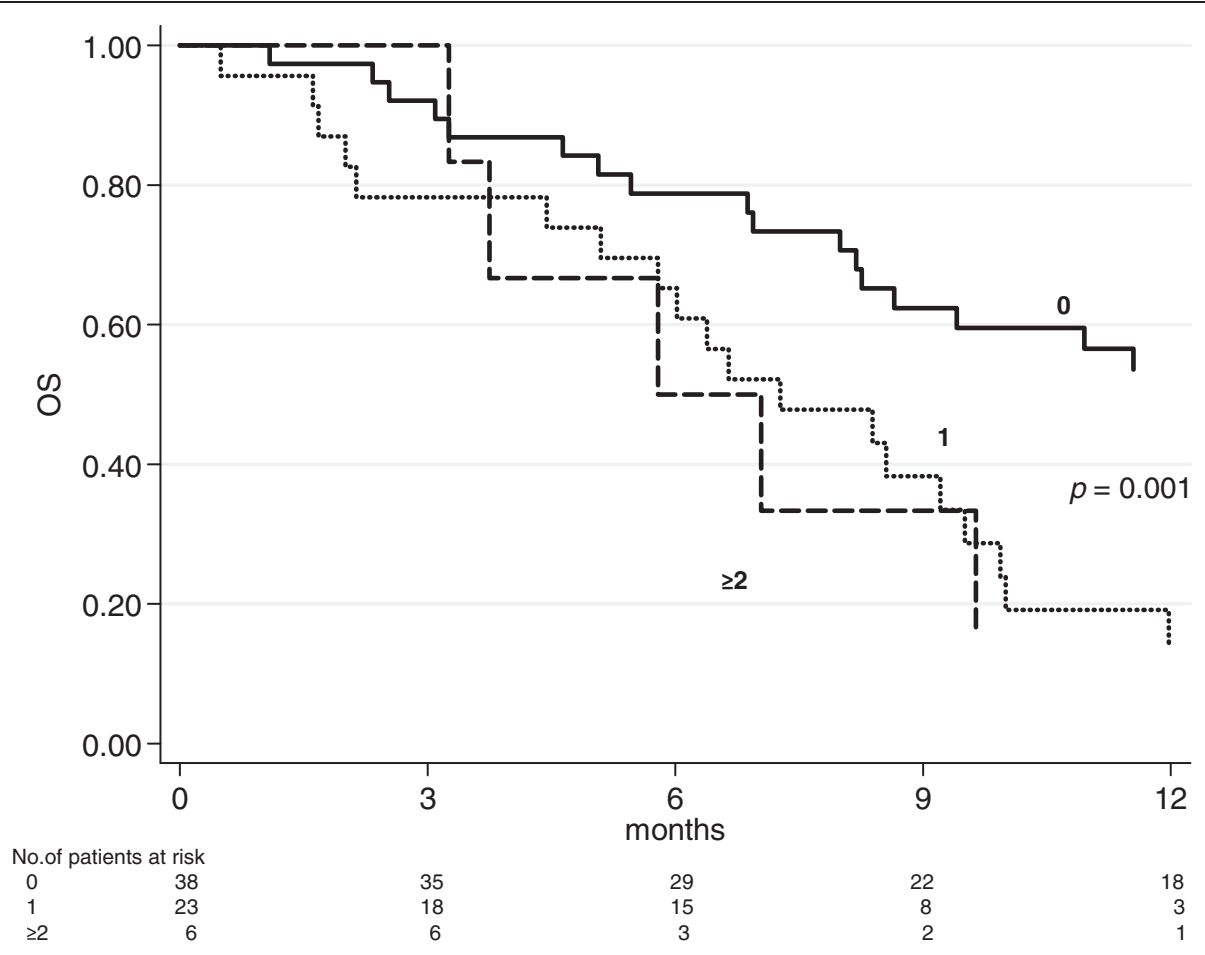

Figure 3 OS on the basis of the number of tumor molecular alterations. A significant difference $(p<0.001)$ was observed among patients harboring no (13.9 months), one (7.3 months) or two (6.4 months) alterations.

has been demonstrated that an activating mutation in $B R A F$ is associated with resistance to treatment with anti-EGFR antibodies [14,15]. However, other studies have reported that $B R A F$ mutations appear to be prognostic rather than predictive as mCRC patients not receiving CTX also have markedly reduced survival when tumors harbor a $B R A F$ mutation [32-34]. All these studies suggest that a $B R A F$ mutation precludes benefit from any type of treatment. Similarly, our multivariate analysis on KRAS wt patients confirmed BRAF mutation as a significant predictor of worse PFS and OS following CTXcontaining treatment.

Conflicting results have been obtained for PIK3CA mutations and CTX response $[6,21,33,35,36]$. In our study exon 9 and 20 mutations of the gene were associated with significantly worse PFS and OS, suggesting that the constitutive kinase activity of the mutated protein may overcome the inhibition signal from CTX. Moreover, in the subgroup of KRAS wild type patients, PIK3CA status was significantly associated with a better PFS and with a better, albeit not statistically significant, OS.

We did not obtain significant results on PTEN alterations, in accordance with some studies [21,27] but in contrast to others in which a correlation was observed between the lack of PTEN expression and response to CTX $[19,37]$. The discordance between the different immunohistochemical studies could be due to a number of factors, e.g. a lack of standardization of the reagents and protocols used; the absence of a single cut off value; or the subjective interpretation of the operators who evaluated the samples from a morphological point of view. As the best cut off to define PTEN positivity has not been clearly established, we used a value of $5 \%$.

\section{Conclusions}

Our study shows that BRAF and PIK3CA mutations are independently associated with worse ORR, PFS and OS, and that patients with wild type KRAS, BRAF and PIK3CA status have a significantly better outcome with respect to patients with at least one alteration. These results suggest that BRAF and PIK3CA could also be taken into consideration in the decision making for CTX-based treatment. Having said that, the number of patients in the present work is too small to reach any definitive conclusions, and larger prospective studies are now needed to validate our findings. Moreover, it would be opportune to confirm the results in a series of patients not treated with CTX in order to exclude the possibility that BRAF and PIK3CA mutations have a prognostic rather than predictive value. 


\section{Abbreviations}

CRC: Colorectal cancer; mCRC: Metastatic colorectal cancer; CTX: Cetuximab; ORR: Overall response rate.

\section{Competing interests}

The authors declare that they have no competing interests.

\section{Acknowledgements}

The authors thank Prof. Rosella Silvestrini for her invaluable scientific contribution and Gráinne Tierney for editing the manuscript.

\section{Author details}

${ }^{1}$ Biosciences Laboratory, IRCCS Istituto Scientifico Romagnolo per lo Studio e la Cura dei Tumori (I.R.S.T.), Via Maroncelli 40, 47014 Meldola (FC), Italy. ${ }^{2}$ Department of Medical Oncology, IRCCS Istituto Scientifico Romagnolo per lo Studio e la Cura dei Tumori (I.R.S.T.), Via Maroncelli 40, 47014 Meldola (FC) Italy. ${ }^{3}$ Unit of Biostatistics and Clinical Trials, IRCCS Istituto Scientifico Romagnolo per lo Studio e la Cura dei Tumori (I.R.S.T.), Via Maroncelli 40, 47014 Meldola (FC), Italy. ${ }^{4}$ Pathology Unit, Morgagni-Pierantoni Hospital, Forlì, taly.

\section{Authors' contributions}

PU and AP conceived the study, participated in its design and drafted the manuscript. LC, EC, SB carried out the molecular analyses. MV, PR, ACG, AR made substantial contributions to acquisition of data. WZ, DC, GLF, DA made substantial contributions to the analysis and interpretation of data. ES performed the statistical analyses. LS revised all histological samples. All authors read and approved the final manuscript.

Received: 17 January 2012 Accepted: 8 May 2012

\section{Published: 8 May 2012}

\section{References}

1. Jemal A, Siegel R, Ward E, Hao Y, Xu J, Murray T, Thun MJ: Cancer statistics, 2008. CA Cancer J Clin 2008, 58:71-96.

2. Meyerhardt JA, Mayer RJ: Systemic therapy for colorectal cancer. N Engl J Med 2005, 352:476-487.

3. Pessino A, Artale S, Sciallero S, Guglielmi A, Fornarini G, Andreotti IC, Mammoliti S, Comandini D, Caprioni F, Bennicelli E, Andretta V, Siena S, Sobrero A: Firstline single-agent cetuximab in patients with advanced colorectal cancer. Ann Oncol 2008, 19:711-716.

4. Jonker DJ, O'Callaghan CJ, Karapetis CS, Zalcberg JR, Tu D, Au HJ, Berry SR, Krahn M, Price T, Simes RJ, Tebbutt NC, van Hazel G, Wierzbicki R, Langer C, Moore MJ: Cetuximab for the treatment of colorectal cancer. N Engl J Med 2007, 357:2040-2048.

5. Cunningham D, Humblet $Y$, Siena $S$, Khayat $D$, Bleiberg $H$, Santoro A, Bets $D$, Mueser M, Harstrick A, Verslype C, Chau I, Van Cutsem E: Cetuximab monotherapy and cetuximab plus irinotecan in irinotecan-refractory metastatic colorectal cancer. N Engl J Med 2004, 351:337-345.

6. Lièvre A, Bachet JB, Le Corre D, Boige V, Landi B, Emile JF, Côté JF, Tomasic G, Penna C, Ducreux M, Rougier P, Penault-Llorca F, Laurent-Puig P: KRAS mutation status is predictive of response to cetuximab therapy in colorectal cancer. Cancer Res 2006, 66:3992-3995.

7. Benvenuti S, Sartore-Bianchi A, Di Nicolantonio F, Zanon C, Moroni M, Veronese S, Siena S, Bardelli A: Oncogenic activation of the RAS/RAF signaling pathway impairs the response of metastatic colorectal cancers to anti-epidermal growth factor receptor antibody therapies. Cancer Res 2007, 67:2643-2648

8. Amado RG, Wolf M, Peeters M, Van Cutsem E, Siena S, Freeman DJ, Juan T, Sikorski R, Suggs S, Radinsky R, Patterson SD, Chang DD: Wild-type KRAS is required for panitumumab efficacy in patients with metastatic colorectal cancer. J Clin Oncol 2008, 26:1626-1634.

9. Karapetis CS, Khambata-Ford S, Jonker DJ, O'Callaghan CJ, Tu D, Tebbutt NC, Simes RJ, Chalchal H, Shapiro JD, Robitaille S, Price TJ, Shepherd L, Au HJ, Langer C, Moore MJ, Zalcberg JR: K-ras mutations and benefit from cetuximab in advanced colorectal cancer. N Engl J Med 2008, 359:1757-1765.

10. Van Cutsem E, Köhne CH, Hitre E, Zaluski J, Chang Chien CR, Makhson A, D'Haens G, Pintér T, Lim R, Bodoky G, Roh JK, Folprecht G, Ruff P, Stroh C, Tejpar S, Schlichting M, Nippgen J, Rougier P: Cetuximab and chemotherapy as initial treatment for metastatic colorectal cancer. $N$ Engl J Med 2009, 360:1408-1417.
11. Bokemeyer C, Bondarenko I, Makhson A, Hartmann JT, Aparicio J, de Braud F, Donea S, Ludwig H, Schuch G, Stroh C, Loos AH, Zubel A, Koralewski P: Fluorouracil, leucovorin, and oxaliplatin with and without cetuximab in the first-line treatment of metastatic colorectal cancer. J Clin Oncol 2009, 27:663-671

12. Yan J, Roy S, Apolloni A, Lane A, Hancock JF: Ras isoforms vary in their ability to activate Raf-1 and phosphoinositide 3-kinase. J Biol Chem 1998, 273:24052-24056.

13. Zhang BH, Guan KL: Activation of B-Raf kinase requires phosphorylation of the conserved residues Thr598 and Ser601. Embo J 2000, 19:5429-5439.

14. Sartore-Bianchi A, Di Nicolantonio F, Nichelatti M, Molinari F, De Dosso S, Saletti P, Martini M, Cipani T, Marrapese G, Mazzucchelli L, Lamba S, Veronese S, Frattini M, Bardelli A, Siena S: Multi-determinants analysis of molecular alterations for predicting clinical benefit to egfr-targeted monoclonal antibodies in colorectal cancer. Plos One 2009, 4:e7287 4.

15. Di Nicolantonio F, Martini M, Molinari F, Sartore-Bianchi A, Arena S, Saletti P, De Dosso S, Mazzucchelli L, Frattini M, Siena S, Bardelli A: Wild-type BRAF is required for response to panitumumab or cetuximab in metastatic colorectal cancer. J Clin Oncol 2008, 26:5705-5712.

16. Karakas B, Bachman KE, Park BH: Mutation of the PIK3CA oncogenes in human cancers. Br J Cancer 2006, 94:455-459.

17. Samuels Y, Diaz LA Jr, Schmidt-Kittler O, Cummins JM, Delong L, Cheong I, Rago C, Huso DL, Lengauer C, Kinzler KW, Vogelstein B, Velculescu VE: Mutant PIK3CA promotes cell growth and invasion of human cancer cells. Cancer Cell 2005, 7:561-573.

18. Rodriguez-Viciana P, Warne PH, Dhand R, Vanhaesebroeck B, Gout I, Fry MJ, Waterfield MD, Downward J: Phosphatidylinositol-3-OH kinase as a direct target of Ras. Nature 1994, 370:527-532.

19. Frattini $M$, Saletti $P$, Romagnani $E$, Martin $V$, Molinari F, Ghisletta $M$ Camponovo A, Etienne LL, Cavalli F, Mazzucchelli L: PTEN loss of expression predicts cetuximab efficacy in metastatic colorectal cancer patients. Br J Cancer 2007, 97:1139-1145.

20. Perrone F, Lampis A, Orsenigo M, Di Bartolomeo M, Gevorgyan A, Losa M, Frattini M, Riva C, Andreola S, Bajetta E, Bertario L, Leo E, Pierotti MA, Pilotti S: $\mathrm{PI} 3 \mathrm{KCA} / \mathrm{PTEN}$ deregulation contributes to impaired responses to cetuximab in metastatic colorectal cancer patients. Ann Oncol 2009, 20:84-90.

21. Sartore-Bianchi A, Martini M, Molinari F, Veronese S, Nichelatti M, Artale S, Di Nicolantonio F, Saletti P, De Dosso S, Mazzucchelli L, Frattini M, Siena S, Bardelli A: PIK3CA mutations in colorectal cancer are associated with clinical resistance to EGFR-targeted monoclonal antibodies. Cancer Res 2009, 69:1851-1857.

22. Jhawer M, Goel S, Wilson AJ, Montagna C, Ling YH, Byun DS, Nasser S, Arango D, Shin J, Klampfer L, Augenlicht LH, Perez-Soler R, Mariadason JM: PIK3CA mutation/PTEN expression status predicts response of colon cancer cells to the epidermal growth factor receptor inhibitor cetuximab. Cancer Res 2008, 68:1953-1961.

23. Kaplan EL, Meier P: Non-parametric estimation from incomplete observation. J Am Stat Assoc 1958, 53:457-481.

24. Lawkess JS: Statistical models and methods for life-time data. New York: John Wiley and Sons; 1982.

25. Cox DR: Regression models and life tables. J Royal Stat Soc 1972, 34:187-220.

26. Laurent-Puig P, Cayre A, Manceau G, Buc E, Bachet JB, Lecomte T, Rougier P, Lievre A, Landi B, Boige V, Ducreux M, Ychou M, Bibeau F, Bouché O, Reid J, Stone S, Penault-Llorca F: Analysis of PTEN, BRAF, and EGFR status in determining benefit from cetuximab therapy in wild-type KRAS metastatic colon cancer. J Clin Oncol 2009, 27:5924-5930.

27. Razis E, Briasoulis E, Vrettou E, Skarlos DV, Papamichael D, Kostopoulos I, Samantas E, Xanthakis I, Bobos M, Galanidi E, Bai M, Gikonti I, Koukouma A, Kafiri G, Papakostas P, Kalogeras KT, Kosmidis P, Fountzilas G: Potential value of PTEN in predicting cetuximab response in colorectal cancer: an exploratory study. BMC Cancer 2008, 8:234.

28. Matallanas D, Romano D, Al-Mulla F, O'Neill E, Al-Ali W, Crespo P, Doyle B, Nixon C, Sansom O, Drosten M, Barbacid M, Kolch W: Mutant K-Ras activation of the proapoptotic MST2 pathway is antagonized by wild-type K-Ras. Mol Cell 2011, 44:893-906.

29. De Roock W, Jonker DJ, Di Nicolantonio F, Sartore-Bianchi A, Tu D, Siena S, Lamba S, Arena S, Frattini M, Piessevaux H, Van Cutsem E, O'Callaghan CJ, Khambata-Ford S, Zalcberg JR, Simes J, Karapetis CS, Bardelli A, Tejpar S: Association of KRAS p.G13D mutation with outcome in patients with chemotherapy-refractory metastatic colorectal cancer treated with cetuximab. JAMA 2010, 304:1812-1820. 
30. Al-Mulla F, Going JJ, Sowden ET, Winter A, Pickford IR, Birnie GD: Heterogeneity of mutant versus wild-type Ki-ras in primary and metastatic colorectal carcinomas, and association of codon-12 valine with early mortality. J Pathol 1998, 185:130-138.

31. Andreyev HJ, Norman AR, Cunningham D, Oates J, Dix BR, lacopetta BJ, Young J, Walsh T, Ward R, Hawkins N, Beranek M, Jandik P, Benamouzig R, Jullian E, Laurent-Puig P, Olschwang S, Muller O, Hoffmann I, Rabes HM, Zietz C, Troungos C, Valavanis C, Yuen ST, Ho JW, Croke CT, O'Donoghue DP, Giaretti W, Rapallo A, Russo A, Bazan V, Tanaka M, Omura K, Azuma T, Ohkusa T, Fujimori T, Ono Y, Pauly M, Faber C, Glaesener R, de Goeij AF, Arends JW, Andersen SN, Lövig T, Breivik J, Gaudernack G, Clausen OP, De Angelis PD, Meling Gl, Rognum TO, Smith R, Goh HS, Font A, Rosell R, Sun XF, Zhang H, Benhattar J, Losi L, Lee JQ, Wang ST, Clarke PA, Bell S, Quirke P, Bubb VJ, Piris Cruickshank NR, Morton D, Fox JC, Al-Mulla F, Lees N, Hall CN, Snary D, Wilkinson K, Dillon D, Costa J, Pricolo VE, Finkelstein SD, Thebo JS, Senagore AJ, Halter SA, Wadler S, Malik S, Krtolica K, Urosevic N: Kirsten ras mutations in patients with colorectal cancer: the 'RASCAL II' study. Br J Cancer 2001, 85:692-696.

32. Tol J, Nagtegaal ID, Punt CJ: BRAF mutation in metastatic colorectal cancer. N Engl J Med 2009, 361:98-99.

33. Souglakos J, Philips J, Wang R, Marwah S, Silver M, Tzardi M, Silver J, Ogino S, Hooshmand S, Kwak E, Freed E, Meyerhardt JA, Saridaki Z, Georgoulias V, Finkelstein D, Fuchs CS, Kulke MH, Shivdasani RA: Prognostic and predictive value of common mutations for treatment response and survival in patients with metastatic colorectal cancer. Br J Cancer 2009, 101:465-472.

34. Ogino S, Nosho K, Kirkner GJ, Kawasaki T, Meyerhardt JA, Loda M, Giovannucci EL, Fuchs CS: CpG island methylator phenotype microsatellite instability, BRAF mutation and clinical outcome in colon cancer. Gut 2009, 58:90-96.

35. Moroni M, Veronese S, Benvenuti S, Marrapese G, Sartore-Bianchi A, Di Nicolantonio F, Gambacorta M, Siena S, Bardelli A: Gene copy number for epidermal growth factor receptor (EGFR) and clinical response to antiEGFR treatment in colorectal cancer: a cohort study. Lancet Oncol 2005, 6:279-286.

36. Prenen H, De Schutter J, Jacobs B, De Roock W, Biesmans B, Claes B, Lambrechts D, Van Cutsem E, Tejpar S: PIK3CA mutations are not a major determinant of resistance to the epidermal growth factor receptor inhibitor cetuximab in metastatic colorectal cancer. Clin Cancer Res 2009, 15:3184-3188.

37. Loupakis F, Pollina L, Stasi I, Ruzzo A, Scartozzi M, Santini D, Masi G, Graziano F, Cremolini C, Rulli E, Canestrari E, Funel N, Schiavon G, Petrini I, Magnani M, Tonini G, Campani D, Floriani I, Cascinu S, Falcone A: PTEN expression and KRAS mutations on primary tumors and metastases in the prediction of benefit from cetuximab plus irinotecan for patients with metastatic colorectal cancer. J Clin Oncol 2009, 27:2622-2629.

doi:10.1186/1479-5876-10-87

Cite this article as: Ulivi et al:: Predictive role of multiple gene alterations in response to cetuximab in metastatic colorectal cancer: A single center study. Journal of Translational Medicine 2012 10:87.

\section{Submit your next manuscript to BioMed Central and take full advantage of:}

- Convenient online submission

- Thorough peer review

- No space constraints or color figure charges

- Immediate publication on acceptance

- Inclusion in PubMed, CAS, Scopus and Google Scholar

- Research which is freely available for redistribution

Submit your manuscript at www.biomedcentral.com/submit 